\title{
EFECTO DE LA ALIMENTACIÓN CON GRASAS PROTEGIDAS EN VACAS DE DOBLE PROPÓSITO ${ }^{1}$
}

\author{
Juan Prisciliano Zárate-Martínez $z^{2}$,Julio Cesar Vinay-Vadillo ${ }^{2}$, Omar Cristóbal Carballo ${ }^{2}$, \\ Víctor Delio Hernández-Hernández ${ }^{2}$,Eugenio Villagómez Amezcua-Manjarres ${ }^{3}$
}

\section{RESUMEN}

Efecto de la alimentación con grasas protegidas en vacas de doble propósito. El objetivo de este trabajo fue determinar la reducción del anestro posparto en vacas con el suministro de grasas protegidas. El estudio se realizó en el Campo Experimental La Posta de Paso del Toro, Veracruz, México. Las vacas fueron asignadas de forma aleatoria a dos grupos: suplementación de grasas protegidas (GP; T1, $\mathrm{n}=20$ ) o sebo (SGP; $\mathrm{T} 2, \mathrm{n}=20$ ) al 2,7\% de la dieta en base seca. Se registró la producción de leche (PL), condición corporal (CC), progesterona y hormonas tiroideas (T3 y T4). Las fuentes de variación fueron dieta, grupo genético y número de partos, y las variables dependientes PL, días al primer estro (DPE), CC y metabolitos. Se determinaron correlaciones entre variables. No se encontró efecto $(p>0,05)$ de tratamiento para la producción de leche, pero sí $(\mathrm{p}<0,01)$ para el primer cuerpo lúteo. La condición corporal 4,5 tuvo la mayor producción láctea $(\mathrm{p}<0,01 ; 16,68 \pm 1,076 \mathrm{~L} / \mathrm{d})$ y el menor número de días al primer estro ( $\mathrm{p}<0,05 ; 31,71 \pm 7,5 \mathrm{~d}$ ). Las hormonas tiroideas no mostraron diferencias $(\mathrm{p}>0,05)$ entre tratamientos: $\mathrm{T} 1=72,4$ y T2 $=72,72 \mathrm{ug} / \mathrm{dl}$. La insulina fue mayor $(\mathrm{p}<0,05)$ en T2 $(6,87 \mathrm{UI})$ que en T1 $(5,26 \mathrm{UI})$. Se concluye que el tipo de grasa no afectó la producción de leche; la GP mejoró el reinicio de actividad ovárica y disminuyó la concentración de insulina sérica.

Palabras claves: Ácidos grasos, actividad ovárica, insulina.

\begin{abstract}
Effect of feeding calcium soaps on double purpose cows. The effect of feeding with protected fats on double purpose cows. The objective of this study was to determine the reduction of post-partum anestrum in cows by supplying protected fats. The study was conducted ad the Experimental field La Posta, Paso del Toro, Veracruz, México. The cows were randomnly assigned to two groups: suplementation with protected fats $(\mathrm{GP} ; \mathrm{T} 1, \mathrm{n}=20$ ) or tallow (SGP; T2, $\mathrm{n}=20$ ) at $2.7 \%$ of a dry weight-based diet. Milk production, physical condition (CC), progesterone and tiroid hormone levels were registered. (T3 and T4). Sources of variation were diet, genetic group and number of calf births, and the dependent variables PL were days to the first estrus (DPE), $\mathrm{CC}$ and meatabolite levels. Correlations among variables were conducted. No effect $(p>0,05)$ of treatments on milk production were observed, but significant effects $(p<0,01)$ for the fist corpus luteum. Physical condition 4,5 had the best milk production $(\mathrm{p}<0,01 ; 16,68 \pm 1,076 \mathrm{~L} /$ day $)$ and lower number of days to the first estrum $(p<0,05 ; 31,71 \pm 7,5 \mathrm{~d})$. Tiroid hormones did not show differences $(\mathrm{p}>0,05)$ among treatments: $\mathrm{T} 1=72,4$ and T2 $=72,72 \mathrm{ug} / \mathrm{dl}$. Insuline was higher $(\mathrm{p}<0,05)$ in T2 $(6,87$ UI) than in T1 $(5,26 \mathrm{UI})$. It is concluded that the type of fat did not affect milk production but stimulated the resumption of ovarian activity and reduced the concentration of insulin in the serum.
\end{abstract}

Key words: Fatty acids, ovarian activity, Insulin.

\footnotetext{
1 Recibido: 28 de febrero, 2011. Aceptado: 28 de octubre, 2011. Proyecto de investigación del CIRGOC. Instituto Nacional de Investigaciones Forestales, Agrícolas y Pecuerias (INIFAP).

2 Campo Experimental La Posta. Instituto Nacional de Investigaciones Forestales, Agricolas y Pecuerias (INIFAP). Km 22,5 carretera Veracruz-Córdoba C.P. 94277, Col. Paso del Toro Municipio de Medellín de Bravo, Veracruz, Ver., México. zarate.juan@inifap.gob.mx (correspondencia); vinay.julio@inifap.gob.mx; cristobal.omar@inifap.gob.mx, hernandez.victordelio@inifap.gob.mx

3 Centro Nacional de Investigación Disciplinaria en Microbiología. Instituto Nacional de Investigaciones Forestales, Agrícolas y Pecuarias (INIFAP). Km 15,5 carretera México-Toluca, Col. Palo Alto 05110 México D.F. villagomez.eugenio@inifap.gob.mx.
} 


\section{INTRODUCCIÓN}

Un manejo adecuado de la alimentación de las vacas puede contribuir a una reducción razonable de los 185 días abiertos actuales a 102, lo que disminuirá el período interpartos de dieciocho meses (trópico mexicano) a trece meses, resultando en un becerro y una lactancia más durante la vida productiva del animal. Se ha estimado que en sistemas de producción bovina con poca tecnología el anestro posparto dura 270 días en promedio, lo que significa que esta condición contribuye con el $72 \%$ del período de días abiertos si se excluye el puerperio. La mayoría de los estudios sobre anestro posparto se han realizado en vacas productoras de carne de origen europeo y se sabe que la nutrición es uno de los factores de mayor importancia que determinan la longitud de dicho parámetro.

El valor energético de los lípidos depende sobre el origen de la grasa añadida. Los ácidos grasos poliinsaturados tienen un efecto negativo sobre el metabolismo de las bacterias celulolíticas en relación con los ácidos grasos saturados y por lo tanto reducen el valor energético de la fracción no lipídica de la dieta. En contraste, se piensa que estos mismos ácidos grasos poliinsaturados tienen una mayor digestibilidad intestinal que los ácidos grasos saturados (Coppock y Wilks 1991). Por otro lado, existen evidencias de que la energía metabolizable (EM) de los ácidos grasos de cadena larga es utilizada de manera más eficiente para propósitos de producción, que la EM proveniente de los ácidos grasos de cadena corta (Lubis et al. 1990, Andrew et al. 1991).

Una posibilidad para incrementar el valor energético de las grasas es protegerlas contra la biohidrogenización bacteriana. Las sales de calcio parecen ser inertes en el rumen y no son tóxicas para las bacterias ruminales por lo cual no tienen efectos negativos sobre la digestión ruminal (Elmeddah et al. 1991). Tales grasas inertes han superado parcialmente el efecto negativo de las grasas normales como los aceites libres y con ácidos grasos de cadenas medias o cadenas insaturadas sobre la fermentación ruminal (Jerred et al. 1990).

Entre los beneficios observados en la inclusión de grasa adicional protegida en la dieta están: 1) incremento en la densidad calórica sin comprometer digestión de la fibra, 2) incremento en el consumo de energía durante la lactación temprana cuando las vacas no consumen el suficiente alimento, 3 ) incrementan la eficiencia de utilización de la energía, 4) incrementan el cociente lipogénico/glucogénico, 5) aumenta el número de folículos de las diferentes clases de tamaño así como el tamaño medio de los más grandes y subordinados y 6) aumenta el porcentaje de la superficie de células lúteas pequeñas y grandes así como el área total ocupada por los lípidos. Debido a que las grasas inertes generalmente son más costosas que las normales, una estrategia económica puede ser la de utilizar normales hasta un máximo tolerado para la digestión ruminal y entonces incrementar hasta una cantidad benéfica mayor mediante grasas inertes (Coppock y Wilks 1991).

Existe la posibilidad de que al incrementar la densidad calórica, la eficiencia energética y el cociente lipogénico/glucogénico mediante el uso de grasas se pueda mejorar el comportamiento reproductivo de los animales. Se ha propuesto que al añadir grasa en la dieta, se puede reducir el balance energético negativo (estimado) y minimizar las pérdidas de peso, mejorando el estado energético y/o nutricional de los animales y por ende su comportamiento reproductivo (Butler y Smith 1989a, Staples et al. 1990). Es posible que los aditivos ricos en energía modulen el reinicio de la función hipotalámica-pituitaria (y finalmente la ovárica) por medio de efectos aún no determinados, sobre el estado energético total del animal. Además se ha observado que una mayor ingestión de grasa tiene efectos directos sobre las estructuras ováricas (Williams et al. 1989, Lucy et al. 1991a, Lucy et al. 1991b) y sobre la concentración de progesterona sérica (Carrol et al. 1990). Sin embargo, la respuesta a la inclusión de grasa adicional en la dieta en términos de fertilidad ha sido variable, por ejemplo se han observado mayores o iguales tasas de fecundación (Carrol et al. 1990, Sklan y Moallem 1991, Lucy et al. 1991). Por otro lado, se ha propuesto que la alimentación adicional de grasa puede reducir la producción calórica corporal y por lo tanto disminuir los efectos del estrés calórico ambiental (Coppock et al. 1987), problema al cual está sometido el ganado cruzado de doble propósito.

En un estudio con vacas cebú, se observó una interacción entre el consumo de grasa protegida y la época de escasez de forraje reduciéndose la duración del anestro posparto (Villagómez et al. 2003). Existe poca información acerca del efecto de las grasas protegidas sobre el reinicio de la actividad ovárica posparto de vacas de doble propósito en el trópico, por lo que es 
oportuno estudiar el suministro de aditivos energéticos a tales animales.

El objetivo de este trabajo fue determinar la reducción del anestro posparto en vacas con el suministro de grasas protegidas.

\section{MATERIALES Y MÉTODOS}

El estudio se realizó durante los años 2003 y 2004 en el Campo Experimental La Posta del Instituto Nacional de Investigaciones Forestales, Agrícolas y Pecuarias (INIFAP), localizado en el km 22,5 de la carretera Veracruz-Córdoba, en Paso del Toro, municipio de Medellín de Bravo, Veracruz, México, a $15^{\circ} 18^{\prime}$ latitud norte, $96^{\circ} 10^{\prime}$ longitud oeste y una altitud de $12 \mathrm{~m}$ sobre el nivel del mar. La región tiene un clima tropical subhúmedo Aw1, con temperatura máxima, media y mínima de $35,3,25$ y $15^{\circ} \mathrm{C}$, respectivamente, una precipitación pluvial media anual de1461 mm y humedad relativa de 77,4\% (García 1989).

Se utilizaron 40 vacas que se encontraban próximas al parto (con dos y tres partos), de la cruza Bos taurus x Bos indicus (50\% Holstein $\mathrm{n}=8 ; 50 \%$ Suizo Pardo $n=8 ; 43 \%$ Holstein $n=8 ; 60 \%$ Holstein $n=8 y$ $75 \%$ Suizo Pardo $n=8$ por cebú). El grupo genético $43 \%$ Holstein se determinó con base en el porcentaje de cruzamientos de las vacas $75 \%$ Holstein, que fueron asignadas a inseminarse con semen de toros cebú y toros cruzados que produjeron este grupo genético. Los animales fueron asignados de forma aleatoria a dos tratamientos, de los cuales uno recibió suplementación energética (GP; T1, n=20) con la adición de sales de calcio de ácidos grasos de cadena larga (Arm \& Hammer) al $2,58 \%$, éstas son grasas protegidas a base de sales de calcio y el otro tratamiento con sebo de res (SGP; T2, n=20) al mismo 2,58\% sin la adición de grasa protegida.

Se utilizó el programa Cornell Net Carcohaydrate \& Protein System (CNCPS) versión 3,1 para el balanceo de las raciones. Los animales pastorearon potreros con zacate Taiwán de 60 días de edad y fueron suplementados con $5,22 \mathrm{~kg} / \mathrm{d}$ de concentrado por animal, en la siguiente composición ( $\mathrm{kg}$ base seca): sorgo (grano molido), 1,18; pasta de soya, 2,00; harina de pescado, 0,40; melaza, 0,40; urea, 0,40; minerales, 0,40; bicarbonato, 0,02; traza, 0,02; grasa, 0,40 (grasa protegida, T1 o Sebo, T2). Las dietas se proporcionaron a los animales durante y al salir del ordeño, desde dos semanas antes del parto hasta el término de la lactancia, ajustando la cantidad de la ración ofrecida (16 kg) hasta que dejaron un 5\% de rechazo, la cual tuvo para los dos grupos una densidad calórica y proteica de la siguiente manera: Energía neta para lactancia (Mcal $/ \mathrm{kg}$ ) $=1,24$ y Energía neta para ganancia $(\mathrm{Mcal} /$ día $)=0,67$. Porcentaje de proteína total $=20,76 \%$ MS; Porcentaje de proteína no degradable $=29,7 \%$ PC; Porcentaje de proteína degradable $=70,3 \% \mathrm{PC}$.

Las vacas estuvieron en un sistema de pastoreo rotacional con siete divisiones, en un área de 16 ha que tenían pastos introducidos y gramas nativas. Los pastos introducidos fueron Insurgentes (Brachiaria brizantha) y Chontalpo o señal (B. decumbens), la grama nativa predominante era Frente de toro o remolino (Paspalum notatum) con porcentajes de proteína y digestibilidad de materia seca de $14 \%$ y $70 \%, 12 \%$ y $75 \%$ y $9 \%$ y $60 \%$ respectivamente; para fertilizar los potreros se aplicaron $400 \mathrm{~kg}$ de nitrógeno $\left(\mathrm{N}_{2}\right)$ por hectárea, fraccionado en seis aplicaciones mensuales de $50 \mathrm{~kg}$ (junio-noviembre) y $100 \mathrm{~kg}$ de fósforo $\left(\mathrm{P}_{2} \mathrm{O}_{5}\right)$, en una sola aplicación al inicio de las lluvias. Como fuente de $\mathrm{N}$ se utilizó urea y de $\mathrm{P}$, en forma de superfosfato de calcio triple.

Las vacas tenían libre acceso a sales minerales y agua; fueron ordeñadas dos veces al día y se encontraban amamantando a sus becerros y éstos solo permanecieron con su madre $7 \mathrm{~h}$ al día. Durante la ordeña sólo se apoyaban con el becerro para estimular la bajada de la leche e inmediatamente después de cada ordeña, salían con la vaca para tomar la leche residual durante media hora para posteriormente ser retirados a un corral y las vacas se llevaban a los potreros; la producción de leche se registró diariamente. Se determinó la condición corporal cada quince días a partir del parto en una escala de cinco puntos (donde 1= muy flaca, y $5=$ obesa incluyendo puntos intermedios), usando examen visual y palpación (Edmonson et al. 1989).

Para determinar la duración del anestro se colectaron muestras de sangre a intervalos de cinco días del primer día posparto hasta la presentación del segundo estro con ovulación. La sangre fue refrigerada por dieciséis horas para su proceso de coagulación y se centrifugó a $700 \mathrm{~g}$ a $5^{\circ} \mathrm{C}$ para la colección de suero. Del suero obtenido se cuantificó progesterona mediante un estuche comercial en fase sólida y la presencia de un cuerpo lúteo fue determinada cuando se cuantificó 
una concentración de progesterona igual o mayor a $1 \mathrm{ng} / \mathrm{ml}$ en dos muestras sanguíneas consecutivas y por palpación rectal. Para determinar la función tiroidea de tiroxina $\left(\mathrm{T}_{4}\right)$ e insulina (INS) séricas se realizó radioinmunoanálisis mediante una fase sólida con estuches comerciales y la triiodotironina $\left(\mathrm{T}_{3}\right)$ se determinó, mediante la técnica de doble anticuerpo en sueros obtenidos con la frecuencia y manejo descritos para la determinación de progesterona.

Se realizó un análisis de varianza mediante el GLM de SAS (2002), donde el efecto fue la dieta anidada en la vaca. La función tiroidea se determinó mediante un análisis de varianza para medidas repetidas (SAS 2002) de los cambios en el perfil posparto de las concentraciones de $\mathrm{T}_{3} \mathrm{y}_{4}$. Los efectos fijos fueron los descritos anteriormente para progesterona y se incluyó en el modelo el efecto de la muestra. Colateralmente se revisaron las correlaciones simples entre las variables reproductivas y las de función tiroidea y se detectaron celos dos veces al día durante media hora. Se utilizó un diseño completamente al azar, las fuentes de variación en el modelo fueron la dieta, el genotipo y el número de partos, las variables dependientes fueron: condición corporal, producción de leche vaca/día, utilizando para esta variable más de tres repeticiones por grupo genético analizado y días al primer estro de los animales en estudio.

\section{RESULTADOS Y DISCUSIÓN}

El tratamiento afectó sólo las variables reproductivas, días al primer estro y aparición del primer cuerpo lúteo, las cuales fueron menores $(\mathrm{p}<0,01)$ para las vacas suplementadas con GP que para SGP (Cuadro 1), pero no se encontraron diferencias $(\mathrm{p}>0,05)$ para la de producción vaca/por tipo de

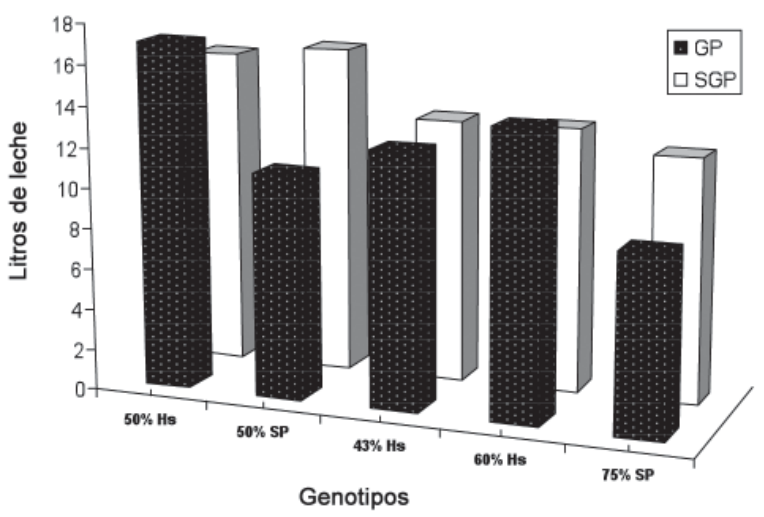

Figura 1. Producción de leche en vacas de doble propósito alimentadas con grasa protegida (GP) y con sebo de res (SGP). Campo Experimental La Posta. Instituto Nacional de Investigaciones Forestales, Agrícolas y Pecuarias (INIFAP). México. 20032004.

grasa (Figura 1). Los días al primer estro por grupo genético fueron de $89,73 \pm 4,64$ y $202 \pm 5,28 \mathrm{~d}$ para los genotipos 50 y $75 \%$ Suizo Pardo respectivamente; de $120 \pm 6,70$ y $155 \pm 2,79$ días para los genotipos 43 y $60 \%$ Holstein respectivamente en el tratamiento con GP, y para el tratamiento SGP fue de $151 \pm 5,96$ y $291,61 \pm 3,95 \mathrm{~d}$ para los genotipos 50 y $75 \%$ Suizo Pardo respectivamente, $153,14 \pm 2,52$ y $219,10 \pm 3,43$ $\mathrm{d}$ en los genotipos 43 y $50 \%$ Holstein respectivamente $(\mathrm{p}<0,01)$. El número de parto y condición corporal afectaron la variable de producción de leche; en donde la condición corporal sobre la producción vaca/línea mostró la mayor producción para la condición corporal 4,5 con $16,68 \pm 1,071(\mathrm{p}<0,01)$ y la presentación más temprana del estro con $31,71 \pm 7,49 \mathrm{~d}(\mathrm{p}<0,05)$; sin

Cuadro 1. Comportamiento productivo y reproductivo de vacas de doble propósito suplementadas con o sin grasas protegidas. Campo Experimental La Posta. Instituto Nacional de Investigaciones Forestales, Agrícolas y Pecuarias (INIFAP). México 2003-2004.

\begin{tabular}{lccc}
\hline Tratamiento & $\begin{array}{c}\text { Producción de leche } \\
\text { (l) }\end{array}$ & $\begin{array}{c}\text { Días al primer } \\
\text { cuerpo lúteo }\end{array}$ & $\begin{array}{c}\text { Días al } \\
\text { primer estro }\end{array}$ \\
\hline Con grasa protegida & $14,88 \mathrm{a} \pm 0,04 \mathrm{a}$ & $82,4 \pm 0,62 \mathrm{a}$ & $150,15 \mathrm{a} \pm 1,68 \mathrm{a}$ \\
Sin grasa protegida & $15,26 \mathrm{a} \pm 0,04 \mathrm{a}$ & $103,83 \pm 1,20 \mathrm{~b}$ & $195,80 \mathrm{~b} \pm 1,38 \mathrm{~b}$ \\
\hline
\end{tabular}

Distintas literales por columna indican diferencias estadísticas $(\mathrm{p}<0,01)$. 
embargo, las vacas con las condiciones corporales más bajas 2 y 2,75 tuvieron una producción de 16,67 $\pm 1,011$ y $15,36 \pm 0,151$, respectivamente, pero a diferencia de las vacas con buena condición corporal (de tres a cuatro puntos en la escala), tuvieron los días al primer estro más prolongados $(\mathrm{p}<0,01), 138,73$ $\pm 19,75$ y $195,44 \pm 2,14$ d respectivamente, lo que indica que existió una relación entre la movilización de grasa corporal y la producción de leche que afecta a la presentación de días al primer estro, en donde al alcanzar la condición corporal de 3,5 se logra una relación inversamente proporcional entre el aumento de la producción de leche y la reducción de los días a la presentación del primer estro posparto en vacas de doble propósito. El número de parto con mayor producción vaca/línea fue para las vacas de ocho partos con 19,782 L $\pm 0,64$ y las vacas con dos partos la menor producción con 13,17 L $\pm 0,47$ (Cuadro 2). Dentro del tratamiento el grupo genético $50 \%$ Holstein mostró una mejor producción vaca/línea en ambos tratamientos; $\mathrm{T} 1=16,69 \pm 0,13$ y T2 $=15,588 \pm 0,13$ y el 50\% SP en el T2 = 16,12 $\pm 0,21$ (Figura 1$)$.

Cuadro 2. Efecto del número de partos sobre la producción de leche diaria en vacas de doble propósito suplementadas con grasas protegidas y/o sebo. Campo Experimental La Posta. Instituto Nacional de Investigaciones Forestales, Agrícolas y Pecuarias (INIFAP). México. 2003-2004.

\begin{tabular}{cc}
\hline No. de parto & $\begin{array}{c}\text { Producción diaria de leche } \\
\text { (l) }\end{array}$ \\
\hline 2 & $13,17 \pm 0,47 \mathrm{a}$ \\
3 & $15,02 \pm 0,507 \mathrm{~b}$ \\
4 & $15,48 \pm 0,48 \mathrm{~b}$ \\
5 & $16,865 \pm 0,49 \mathrm{c}$ \\
6 & $16,75 \pm 0,49 \mathrm{c}$ \\
8 & $19,78 \pm 0,64 \mathrm{~d}$ \\
\hline
\end{tabular}

Distintas literales indica diferencias estadísticas $(p<0,01)$.

En el caso de las hormonas metabólicas $\mathrm{T}_{3}$ y $\mathrm{T}_{4}$ no se encontraron diferencias $(\mathrm{p}<0,05)$ entre tratamientos, pero si una tendencia de la insulina a disminuir $(\mathrm{p}<0,05)$ en el tratamiento con grasa protegida como se observa en la Figura 2 (A, B y C). Los valores de los perfiles de $\mathrm{T}_{3} \mathrm{y} \mathrm{T}_{4}$ observados en este trabajo son los valores de hormonas tiroideas encontrados en vacas de doble propósito durante la lactancia temprana con metabolismo energético positivo.

Debido a que no se encontraron diferencias entre las hormonas $\mathrm{T}_{3}$ y $\mathrm{T}_{4}$ para ninguno de los dos tratamientos se agruparon todos los animales para obtener el perfil hormonal de dichas hormonas (Figuras 3A y $3 \mathrm{~B}$ ), en donde se pudo observar un comportamiento similar a lo largo de las primeras once semanas para $\mathrm{T}_{3}$ $\mathrm{y} \mathrm{T}_{4}$, y al inicio de la lactancia niveles más bajos de las dos hormonas en la semana dos, donde se ve un claro efecto de homeorresis justo cuando las vacas deben superar el estado de estrés que les impone la lactación, para posteriormente a la semana tres remontar los niveles de 78 y $4,18 \mathrm{ng} / \mathrm{dl}$ respectivamente.

En diferentes estudios se ha encontrado que las concentraciones de colesterol, estimulado por la alimentación con grasas, incrementa la síntesis de progesterona por las células foliculares y lúteas de los ovarios, ya que los ácidos grasos pueden producir un incremento plasmático de progesterona. Además, concentraciones de ácido linoleico y linolénico pueden deprimir la secreción y formación de $\mathrm{PGF}_{2 \alpha}$ provocando una prolongada y mayor síntesis y secreción de progesterona de las células de la granulosa y células luteales (Staples et al. 1998).

Por lo anterior se atribuyen dichos efectos al menor número de días de la presentación del primer CL y los días al primer estro para las vacas suplementadas con GP ya que el producto comercial Megalac asegura la absorción a nivel de intestino delgado de hasta un $37 \%$ de ácidos grasos como el linoleico. Utilizando grasas en la alimentación, se puede mejorar la condición corporal de las vacas mantenidas en sistemas de pastoreo en un punto y medio (de 2 a 3,5 ) en donde al alcanzar la condición corporal de 3,5 se logra una tendencia a aumentar la producción de leche y a reducir los días a la presentación del primer estro posparto en vacas de doble propósito (Figura 1), lo que representa un mejor comportamiento reproductivo entre los grupos tratados con GP tal como lo propone Butler y Smith (1989b) y Staples et al. (1990) que al añadir grasa en la dieta se puede reducir el balance energético negativo (estimado) y minimizar las pérdidas de peso, mejorando el estado nutricional de los animales y por ende su comportamiento reproductivo; pero no se observó una mejor producción de leche coincidiendo con lo documentado por Holter et al. (1992) que al incluir aceite de soya suministrado al $5 \%$ en el concentrado 

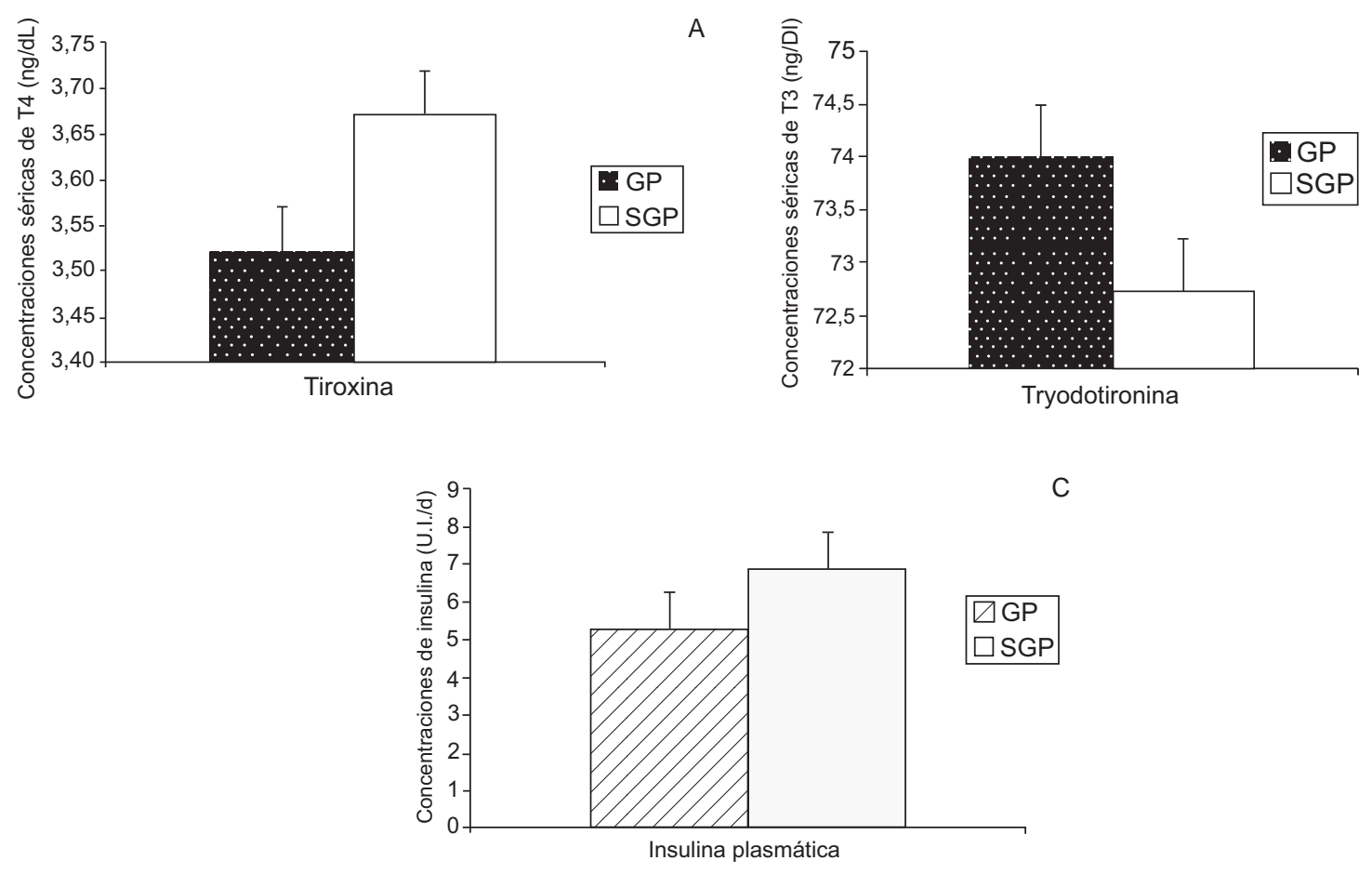

C

Figura 2. Efecto de la inclusión de Grasas Protegidas (GP) sobre la concentración sérica de hormonas metabólicas en vacas de doble propósito. A. Concentraciones séricas de hormona Tiroxina $\left(\mathrm{T}_{4}\right)$; B. Concentraciones séricas de hormona Triyodotironina $\left(\mathrm{T}_{3}\right)$; C. Concentraciones séricas de Insulina. Campo Experimental La Posta. Instituto Nacional de Investigaciones Forestales, Agrícolas y Pecuarias (INIFAP). México. 2003-2004.

A

Perfil de la concentración de la triyodotironina

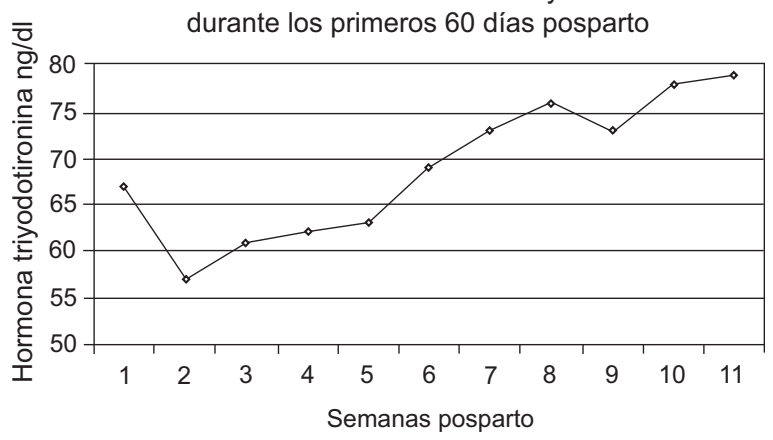

Perfil de la concentración de la tiroxina

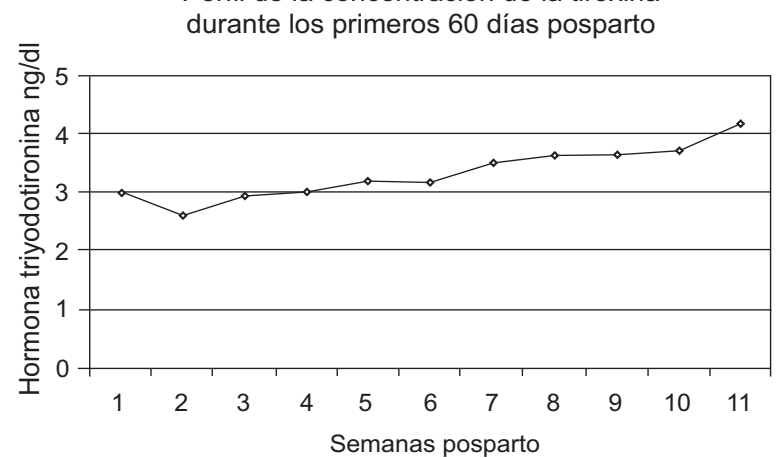

Figura 3. Perfiles de hormonas metabólicas en vacas de doble propósito. A. Perfil sérico de la hormona Tiroxina $\left(\mathrm{T}_{4}\right)$ durante los primeros $60 \mathrm{~d}$ posparto; B. Perfil sérico de la hormona Triyodotironina $\left(\mathrm{T}_{3}\right)$ durante los primeros 60 días posparto. Campo Experimental La Posta. Instituto Nacional de Investigaciones Forestales, Agrícolas y Pecuarias (INIFAP). México. 2003-2004. 
en una ración con cerca del $33 \%$ de heno de pasto, redujeron las pérdidas de metano pero no mejoraron la conversión de energía metabolizable en leche, sin embargo la producción vaca/línea (14,8 y 15,26 l de leche) observada para ambos tratamientos suplementados con y sin grasa protegida superó en un $375 \%$ al promedio de producción de leche de la región (4 litros de leche/ vaca/día). Por otra parte en los resultados obtenidos por grupo genético el efecto de la adición de GP es favorable sobre la adición de sebo para los grupos genéticos de 43 a $60 \%$ B. taurus x B. indicus, sin embargo en los animales con $75 \%$ de $B$. taurus x $B$. indicus no fue así, lo que nos indica que existen otros efectos como pudiera ser la producción calórica corporal que afecta a los animales con una menor resistencia al estrés calórico, en condiciones de los sistemas de doble propósito en pastoreo a diferencia de lo propuesto por Coppock et al. (1987) en donde la alimentación adicional de grasa puede reducir la producción calórica corporal y por lo tanto disminuir los efectos del estrés calórico animal.

El efecto sobre la concentración de insulina en el suero sanguíneo observado en diferentes trabajos de investigación suplementando grasas en la dieta de vacas han arrojado diferentes resultados; sin embargo en la mayoría de estos trabajos (Staples et al. 1998), la suplementación con grasas en vacas lecheras deprimió la concentración sérica de insulina de manera significativa al igual que en el presente trabajo.

Tejidos de células de la granulosa tendían a producir menos IGF-I cuando eran cultivados con insulina y hormona del crecimiento (Spicer et al. 1993), ya que el IGF-I es un potente estimulador de las células de la granulosa, por lo que bajas concentraciones de insulina pueden resultar de un gran secuestro de insulina plasmática por los tejidos, incluyendo los del tracto reproductivo para estimular el crecimiento folicular. La suplementación con grasas puede ser que permita al IGF-I estimular positivamente el desarrollo folicular.

Desde el punto de vista nutricional la inclusión de grasas protegidas en la dieta de vacas de doble propósito contra suplementación energética sin grasas protegidas (sebo) no mejoró la producción de leche, pero sí el comportamiento reproductivo.

La condición corporal al parto y de los primeros días posparto es un factor determinante en el comportamiento productivo y reproductivo de vacas de doble propósito.

En cuanto a las hormonas metabólicas analizadas, en lo que se refiere a la función tiroidea no hubo diferencias entre el tratamiento con grasa y sin grasa protegida, pero si una tendencia significativa a la disminución de insulina en el tratamiento con grasa protegida. La mejoría en el comportamiento reproductivo acompañado de una disminución de las concentraciones sanguíneos de insulina en los animales suplementados con grasa protegida, puede deberse a una disminución de glucosa en la sangre al obtener el aporte energético de la fracción lipídica en las dietas que tienen una mayor digestibilidad intestinal aumentando el cociente lipogénico/ glucogénico. Sin embargo, ésta es una evidencia que habría que investigar con más detalle. La inclusión de grasa protegida en la dieta de vacas de doble propósito permitió una producción de hasta $15 \mathrm{~kg}$ de leche vaca/ día y disminuyó el número de días al primer estro posparto, aún con la presencia del becerro durante siete horas al día.

\section{AGRADECIMIENTOS}

Se agradece al CONACYT, al Sistema de Investigación del Golfo de México (SIGOLFO), al Laboratorio de Reproducción Animal del CENID Microbiología INIFAP, al Centro de Neurología de la UNAM y al Campo Experimental "La Posta" de Paso del Toro Veracruz, por el financiamiento y la ayuda incondicional que brindaron para realizar este trabajo de investigación con No. de proyecto 98-01-033-V.

\section{LITERATURA CITADA}

Andrew, SM; Tyrrell, HF; Reynolds, CK; Erdman RA. 1991. Net energy for lactation of calcium salts of long-chain fatty acids for cows fed silage-based diets. J. Dairy Sci. 74:2588-2595.

Butler, WR; Smith, R. 1989a. The relations between energy balance, milk production, and pospartum reproductive function in dairy cattle. J. Dairy Sci. 50:919-928.

Butler, WR; Smith, DR. 1989b. Relationships between energy balance and reproductive function in dairy cattle. J. Dairy Sci. 72:767-783.

Carrol, DJ; Jerred, MJ; Grummer, RR; Combs, DK; Pierson, RA; Hauser, ER. 1990. Effects of fat supplementation and immature alfalfa to concentrate ratio on plasma progesterone, energy balance, and reproductive traits of dairy cattle. J. Dairy Sci. 73:2855-2863. 
Coppock, CE. 1985. Energy nutrition and metabolism of the lactating dairy cow. J. Dairy Sci. 68:3403-3500.

Coppock, CE, Lanham, JK, Horner, JL. 1987. A review of the nutritive value and utilization of whole cottonseed, cottonseed meal and associated byproducts by dairy cattle. Anim. Feed Sci. Technol. 18:89.

Coppock, CE; Wilks, DL, 1991. Supplemental fat in high energy rations for lactating cow: Effects on intake, digestion, milk yield, and composition. J. Anim. Sci. 69:3826-3835.

Edmonson, AJ; Lean, IJ; Weaver, LD; Farver, T; Webster, G. 1989. A body condition scoring chart for Holstein dairy cows. Journal of Dairy Science. 72:68-78.

Elmeddah, Y; Doreau, M; Michalet-Doreau. 1991. Interaction of lipid supply and carbohydrates in the diet of sheep with digestibility and ruminal digestion. J. Agric. Sci. (Camb) 116:437-444.

García, ME. 1989. Apuntes declimatología. 6 ed. Universidad Nacional Autónoma deMéxico (UNAM). México D.F. p. 155.

Holter JB, Hayes HH, Urban WE JR., 1992. Energy balance and lactation respons in Holstein cows supplemented with cottonseed with or without calcium soap. J. Dairy Sci. 75:1480-1494.

Jerred MJ, Carrol DJ, Combs DK, Grummer RR, 1990. Effects of fat supplementation and immature alfalfa to concentrate ratio on lactation performance of dairy cattle. J. Dairy Sci. 73:2842-2850.

Lubis D, Van Horn HH, Harris Jr B, Bachman KC, Emanuele SM, 1990. Response of lactating dairy cows to protected fats or whole cottonseed in low or high forage diets. J. Dairy Sci. 73:3512-3519.

Lucy, MC; Staples, CR; Michel, FM; Thatcher, WW. 1991a. Energy balance and and size and number of ovarian follicles detected by ultrasonography in early pospartum beef cows. J. Dairy Sci. 74:473-480.

Lucy, MC; Staples, CR; Michel, FM; Thatcher, WW. 1991b. Effect of feeding calcium soaps to early postpartum dairy cows on plasma prostaglandin F2alpha, luteinzing hormone, and follicular growth. J. Anim. Sci. 74:483-489.

SAS (Statistical Analysis System). 2002. User's guide. Version 9.0. SAS Institute Inc., Cary, NC, USA. 466 p.

Sklan, D; Moallem, U. 1991. Effect of feeding calcium soaps of fatty acids on production and reproductive responses in high producing lactating cows. J. Dairy Sci. 74:510-517.

Spicer LJ, Alpizar E and Echternkamp SE. 1993. Effects of insulin, insulin-like growth factor I and gonadotrophins on bovine granulosa cell proliferation, progesterone production in vitro. Journal Animal Science 71:1232-12421.

Staples, CR; Thatcher, WW; Clark, JH. 1990. Relationship between ovarian activity and energy status during early pospartum period of high producing dairy cows. J. Dairy Sci. 73:938-944.

Staples, CR; Burke, JM; Thatcher, WW. 1998. Influence of suplemental fats on reproductive tissues and performance of lactating cows. J.Dairy Sci. 81:856-871.

Villagómez-Amezcua Manjarres E, Zárate-Martínez, JP, Arellano-Martínez, H; Hernández-Hernández, VD; Fajardo-Guel, J. 2003. Efecto de la estación y la inclusión de grasas saponificadas sobre el anestro posparto y la función tiroidea de vacas cebú. Tec. Pecu. Méx. 41 (3):239-250.

Williams GL. 1989. Modulation of luteal activity in postpartum beef cows through changes in dietary lipid. J. Anim. Sci. 67:785-793. 